\title{
Characteristics of Alkali Species Release from a Burning Coal/Biomass Blend
}

\author{
Yingzu Liu ${ }^{1,2}$, Yong $\mathrm{He}^{1}$, Zhihua Wang ${ }^{1, *}$, Jun Xia ${ }^{2, *}$, Kaidi Wan $^{1}$, Ronald Whiddon ${ }^{1}$, Kefa \\ $\mathrm{Cen}^{1}$
}

1 State Key Laboratory of Clean Energy Utilization, Zhejiang University, 310027, Hangzhou, P.R.

China

2 Department of Mechanical and Aerospace Engineering \& Institute of Energy Futures, Brunel

University London, Uxbridge UB8 3PH, UK

${ }^{*}$ Corresponding authors:

(1) Zhihua Wang, Tel: +86-571-87953162, Fax:+86-571-87951616, Email: wangzh@zju.edu.cn;

(2) Jun Xia, Tel: +44 (0)1895 265 433, Fax: +44 (0)1895 256 392, Email: jun.xia@brunel.ac.uk

\begin{abstract}
Solvent fractionation, Laser induced breakdown spectroscopy (LIBS), X-ray Diffraction (XRD) and chemical analysis were applied to binary fuel mixtures of Zhundong coal and cornstalk agricultural class to investigate the release characteristics of alkali species during co-firing of coal and biomass. As the biomass proportion increases, the water-soluble, $\mathrm{NH}_{4} \mathrm{Ac}$-soluble and $\mathrm{HCl}$-soluble alkali species interconvert; the extent of the conversion depends on the composition of the blend. From LIBS measurements, it was found that adding the biomass accelerates combustion and outgassing processes.
\end{abstract} The higher the proportion of the biomass in the blend, the earlier the peak concentrations of alkali appear, and the magnitude of peak concentrations of sodium and potassium decrease and increase, respectively. Furthermore, the interaction between coal and biomass can generate crystals causing the eutectic melting phenomenon (similar to feldspar in XRD results), which results in a sharp decline of the ash fusion temperatures (AFTs). The results not only provide the information of fundamental transformation but also guide industrial co-firing applications of lignite and agricultural class biomass to reduce the risk of ash deposition.

Keywords: Co-firing; alkali metals; fractionation; LIBS; XRD 


\section{Introduction}

With the growing concern about the shortage and environment impacts of fossil fuels, there is a great demand for the development of bioenergy utilization. As a renewable energy source, biomass is also considered to be $\mathrm{CO}_{2}$-neutral, because the $\mathrm{CO}_{2}$ released during combustion is sourced from near term carbon fixation via photosynthesis [1]. Co-firing and co-gasification of fossil fuels with biomass are two currently realizable methods of using biomass to replace some coal in energy production. These methods not only reduce $\mathrm{SO}_{2}, \mathrm{NO}_{\mathrm{x}}$ and greenhouse gas emissions [2, 3], but also improve the efficiency of fuel utilization [4, 5]. Moreover, retrofitting an existing coal-fired boiler to be co-fueled is significantly cheaper than building a new biomass-fired plant [6]. However, many challenges still need to be overcome in retrofitting coal-fired devices for co-firing [7,8], particularly in the areas of (i) fuel collection, (ii) devolatilization of coal/biomass fuel blends, (iii) ignition and flame stability of co-combustion of coal and biomass, (iv) char burning and burnout characteristics and (v) ash formation and deposition problems.

In general, biomass contains a greater concentration and a wider variety of volatile elements than coal. These may be released during co-combustion to varying effect. For example, potassium is more prevalent in biomass than in most common coals [9]. This alkali metal species evaporates during combustion and the vapor condenses and reacts with convective heat exchange surfaces, causing fouling and corrosion. According to Obernberger [10], the potassium vapor nucleates with $\mathrm{Cl}^{-}$or $\mathrm{CO}_{3}{ }^{2-}$, forming $\mathrm{KCl}$ or $\mathrm{K}_{2} \mathrm{CO}_{3}$, which readily condenses on heat exchanger surfaces, causing serious corrosion. During biomass combustion, the whole furnace is subjected to deposit formation, with the zones most exposed for corrosion being the ceiling of the furnace, close to the exhaust exit, and the top of throat where fuel is enters the furnace [11]. This problem is common to coal combustion as well. For example, Zhundong 
coal, which is projected to be one of the most abundant coalmine reserves in China, contains a high concentration of sodium compounds [12]. During the combustion of Zhundong coal, severe fouling and slagging have been encountered arising from the release of sodium in the boiler [13]. Therefore, understanding the conversion and release dynamics of $\mathrm{Na}$ and $\mathrm{K}$ during coal-biomass combustion processes is essential to increase utilization of blended biomass and coal fuel mixtures.

The following factors influence ash deposition during blended coal/biomass fuel combustion [14]:

(i) The elemental composition of the mixture. According to Theis [15] and Robinson [16], mole ratios of chloride $(\mathrm{Cl})$ to sulfur $(\mathrm{S})$ greater than 0.15 in residue were characterized by increased ash deposition. During co-combustion of peat and bark, sulfur (S) was found to inhibit ash deposition through sulfation of alkali species and a decreased chloride $(\mathrm{Cl})$ concentration was noted in the residue. Wang et al. [17] investigated the sintering characteristics of rye straw ash, and found the severe sintering that occurs in rye straw ash was caused by the formation and fusion of low temperature $\mathrm{K}$-silicates and $\mathrm{K}$-phosphates. The reduction of $\mathrm{K} / \mathrm{Ca}$ ratio can promote formation of high temperature silicates and calcium rich $\mathrm{K}$-phosphates and hinder aggregation of ash melts and further formation of large ash slag.

(ii) The mass ratio between biomass and coal. It is the general trend that increasing the proportion of biomass in the fuel blend will increase the ash deposition. Hayrinen et al. [18] used plasma-excited atomic resonance spectroscopy for online measurement of alkali metals in a $20 \mathrm{~kW}$ bubbling fluidized bed and found that $30 \%$ addition of coal to the biomass reduced alkali concentrations by $44-64 \%$. They attributed this reduction to the conversion of alkali chlorides and hydroxides to sulfates and silicates. Abreu et al. [19] investigated the co-firing of bituminous coal with olive stones and pine sawdust, and discovered that co-firing of the coal with olive stones increased ash 
deposition rates compared to the unblended coal. The residues contain a high potassium composition, which increases the ash adhesion. In contrast, blending pine saw dust with the coal decreased the deposition rate as compared with the unblended coal due to low ash and the low alkali concentration of saw dust.

(iii) Combustion temperature. Theis et al. [20] used an air-cooled probe at various probe surface temperatures between 475 and $625^{\circ} \mathrm{C}$ to collect ash deposits from burning mixtures of peat with bark and peat with straw in an entrained flow reactor. The results showed that the probe surface temperature had no effect on the deposition rate when burning pure peat; however, when burning bark, either alone or blended with peat, the deposition rate decreased as the probe surface temperature increased.

(iv) Other factors: additives, particle diameter, etc. Westberg et al. [21] added hydrogen chloride to the combustion chamber and noted a considerable increase of both potassium and chlorine in the secondary cyclone and bag filter ashes. Kwong et al. [22] examined the biomass grinding size for co-firing coal with bamboo, and noticed an appreciable change in the fuel burning rate and pollutant emissions at their experimental conditions. According to Holtmeyer et al. [23], a larger biomass particle size can lead to greater NO conversion in the co-firing of pulverized coal and sawdust. According to $\mathrm{Wu}$ et al. [24] and Jiang et al. [25], the volatile-char interaction mechanism plays an important role in alkali release during biomass/coal combustion.

Numerous optical diagnostics techniques have been used to study the release of elemental alkali and alkali compounds in order to understand the release characteristic of alkali during the biomass or coal combustion. Among these techniques are collinear photo-fragmentation atomic absorption spectroscopy (CPFAAS) [26], laser induced fragmentation fluorescence (ELIF) [27], tunable diode laser 
absorption spectroscopy (TDLAS) [28], planar laser-induced fluorescence (PLIF) [29] and laser-induced breakdown spectroscopy (LIBS) [30]. Application of these techniques to co-firing biomass and coal will provide valuable information about temporal release of alkali during combustion.

In this study, online and offline methods were employed to investigate temporal alkali release and the transformation of alkali in the residual solid during the co-firing process. For offline measurement, a chemical fractionation method was employed to analyze the classes of the sodium and potassium species in the fuel and ash to determine the transformation of alkali during the cofiring. This will be very useful for developing the alkali release and transformation mechanism and providing detailed information for future sodium release inhibition work. For online measurement, laser induced breakdown spectroscopy (LIBS) [31] was used to measure the temporally resolved release characteristics of sodium and potassium. It can help fundamental research field to investigate the correlation between combustion and alkali release, and also help to determine the specific period of combustion with the largest risk of fouling and corrosion. Finally, X-ray diffraction (XRD) was used to analyze the ash composition and the ash fusion temperatures (AFTs) to determine eutectic melting phenomenon as well as a ternary phase diagram. Through the combination of offline, online and residual measurement, it is our intent to develop a detailed understanding of the co-firing process that characterizes the unburnt coal/biomass particle, the temporal alkali release during combustion and the ash residue properties.

This study can be used to identify specific periods of combustion with the largest risk of fouling and corrosion, aid in developing an alkali release and transformation mechanism and provide detailed information for future sodium release inhibition work. In addition, it will increase the fundamental understanding of alkali metal emission during coal/biomass co-firing and guide real world application 
of industrial co-firing of corn stalk agricultural class biomass with Zhundong lignite to reduce fouling and slagging.

\section{Materials and Methods}

\subsection{Solid fuels}

Co-firing experiments were conducted using binary of Zhundong brown coal and cornstalk biomass. Zhundong brown coal, from a large reserve located in Xinjiang Province of China, is known to contain high sodium and calcium compositions [32]. Cornstalk is a typical biomass and is considered as a promising surrogate solid fuel for carbon reduction when used in combustion applications [33]. Cornstalk biomass has a relatively high potassium concentration. Both solid fuels were ground and sieved to select sub $75 \mu \mathrm{m}$ particles. The blended coal-biomass fuels were made by mixing the pulverized coal and biomass in different ratios by weight. The proximate analyses and ultimate analyses for each fuel sample are given in Table 1. The proximate analyses were determined according to the Chinese National Standard GB/T 212-2008 and the ultimate analyses were determined according to the Chinese National Standard GB/T 476-2008 (carbon and hydrogen), GB/T 19227-2008 (nitrogen), and GB/T 214-2007 (sulfur). Contrasting the analyses of coal with biomass, the coal contains a much higher proportion of fixed carbon. The atomic ratio of oxygen to carbon, which can reflect the concentration of oxygen functional groups [34], increases from 0.208 in coal to 1.121 in biomass. This suggests that the biomass fuel will ignite more easily and burn more vigorously than the coal.

Table 1. Chemical analyses of the solid fuel samples

\begin{tabular}{|c|c|c|c|c|c|c|}
\hline & & Coal & & al / Biom & & Biomas: \\
\hline & & Case 1 & Case 2 & Case 3 & Case 4 & Case 5 \\
\hline & & $100 \%$ & $80: 20$ & $50: 50$ & $20: 80$ & $100 \%$ \\
\hline Proximate & Moisture & 9.85 & 10.33 & 10.92 & 11.44 & 11.6 \\
\hline
\end{tabular}




\begin{tabular}{|c|c|c|c|c|c|c|}
\hline analysis(wt.\%, & Ash & 4.23 & 5.06 & 5.36 & 6.06 & 7.85 \\
\hline \multirow[t]{2}{*}{ air dry basis) } & Volatile & 28.72 & 35.29 & 47.09 & 58.32 & 64.21 \\
\hline & Fix Carbon & 57.2 & 49.32 & 36.63 & 24.18 & 16.34 \\
\hline \multicolumn{2}{|c|}{ Calorific value (J/g) } & 24462 & 22743 & 19961 & 17738 & 15755 \\
\hline Ultimate & Carbon & 79.29 & 74.08 & 64.45 & 53.80 & 43.97 \\
\hline analysis(wt.\%, & Hydrogen & 2.89 & 3.49 & 4.06 & 4.25 & 4.53 \\
\hline dry ash free & Nitrogen & 0.88 & 1.57 & 1.61 & 1.67 & 1.83 \\
\hline \multirow[t]{2}{*}{ basis) } & Sulfur & 0.43 & 0.44 & 0.42 & 0.34 & 0.36 \\
\hline & Oxygen & 16.50 & 20.42 & 29.46 & 39.96 & 49.31 \\
\hline
\end{tabular}

\subsection{Identification of sodium and potassium classes}

In order to identify different classes of sodium and potassium in the blended fuel or ash, a chemical fractionation method was employed [35, 36]. The various classes of alkali are identified according to their solubility in different solvents. First, $1 \mathrm{~g}$ of the sample was added to $100 \mathrm{ml}$ water at $333 \mathrm{~K}$ and held for 24 hours under constant stirring. The mixture was filtered and the the amount of water-soluble sodium and potassium in the filtrate was analyzed by inductively coupled plasma atomic emission spectroscopy (ICP-AES). The solvation process was repeated by suspending the solid residue in $100 \mathrm{ml}$ $1 \mathrm{~mol} / \mathrm{L} \mathrm{NH}_{4} \mathrm{Ac}$ and then $100 \mathrm{ml} 1 \mathrm{~mol} / \mathrm{L} \mathrm{HCl}$, with ICP-AES measurement of the filtrate in each case. The residue remaining after the $\mathrm{HCl}$ extraction was digested in strong acid and also analyzed by ICP-AES. The chemical analysis for each case was repeated three times and the average result is shown along with error bars where applicable.

By this method the alkali compounds can be categorized into four classes [36]. The first class consists of water-soluble materials such as alkali sulfates and chlorides. The second class contains ion-exchangeable cations, which are bound to the organic molecular structure containing nitrogen $(\mathrm{N})$ or oxygen (O). The third class consists of the compounds soluble in hydrochloric acid, which are believed 
to be bound to clays by ionic bonds. The last class is the residue that contains non-soluble materials, such as sodium silicate.

\subsection{LIBS measurement and signal calibration.}

LIBS was used to measure the sodium and potassium concentrations in the gas phase above a single fuel pellet while burning. The design and principle of the LIBS system can be found in our previous work [31,37]. Approximately $50 \mathrm{mg}$ of the fuel mixture was pressed into a $4 \mathrm{~mm}$ spherical pellet, which was suspended with two ceramic rods $(\mathrm{d}=1 \mathrm{~mm})$ at $10 \mathrm{~mm}$ above the burner plate center. A laser beam at the fundamental wavelength of Nd:YAG, $1064 \mathrm{~nm}$, was focused $10 \mathrm{~mm}$ above the fuel particle. A laminar premixed burner was used to provide a flat flame to ignite the coal/biomass particle. The main gas composition in the fuel burning environment is $3.9 \% \mathrm{O}_{2}, 7.6 \% \mathrm{CO}_{2}, 15.4 \% \mathrm{H}_{2} \mathrm{O}$ and $72.8 \%$ $\mathrm{N}_{2}$, as calculated by CHEMKIN 3.7 with the GRI 3.0 mechanism. The temperature at the location of the fuel pellet was $\sim 1427^{\circ} \mathrm{C}$, which was measured by an S-type thermocouple. An Ocean Optics USB4000 spectrometer was used to collect the LIBS signal.

To achieve quantitative measurements of Na and K, the LIBS system was calibrated by the method outlined in [31]. For calibration, an ultrasonic vaporizer was used to generate a fog of sodium chloride $(\mathrm{NaCl})$ and potassium chloride $(\mathrm{KCl})$ solution in a vapor chamber. The fuel/air mixture was passed through the vapor chamber before being burnt. Based on the mass loss from the seeding solution, the average seeding rate of $\mathrm{NaCl}$ and $\mathrm{KCl}$ solution was $0.69 \mathrm{~g} / \mathrm{min}$. After correcting for self-absorption by sodium atoms in the plasma and the calibration flame [30], a linear relationship was obtained between the LIBS intensity and the concentration of alkali elements. For the present setup, the linear relation between the LIBS signal and the sodium and potassium concentration are:

$$
I_{L I B S, N a}=2403 \cdot C_{N a} \quad R^{2}=0.96
$$




$$
I_{L I B S, K}=1927 \cdot C_{K} \quad R^{2}=0.97
$$

where $I_{L I B S, N a}$ and $I_{L I B S, K}$ are the LIBS signals of sodium and potassium, respectively; $C_{N a}$ and $C_{K}\left(\mathrm{mg} / \mathrm{m}^{3}\right)$ are the seeding concentrations of sodium and potassium in the calibration flame, respectively. For LIBS measurement, each measurement is repeated three times and the average result is shown along with error bars which indicate the statistical uncertainty of the measurements.

\subsection{Ash compositions and fusion temperature determination}

The co-firing residues were prepared in a muffle furnace at $815^{\circ} \mathrm{C}$ in accordance with the Chinese national standard GB/T 1574-2007. The major elemental compositions were analyzed in the same manner as the wet chemical analysis methods. The ash compositions are shown in Table 2. For coal, the ash has a high proportion of sodium, calcium and iron; while for biomass, the ash has a very low proportion of these elements, but contains appreciable levels of silicon and potassium. Consequently, as the mixing ratio of the biomass increases (from Case 1 to Case 5), the proportions of $\mathrm{Na}, \mathrm{Fe}$ and $\mathrm{Ca}$ decrease and those of $\mathrm{Si}, \mathrm{K}$ increase in the ash.

Table 2. Ash composition of co-firing samples.

\begin{tabular}{cccccc}
\hline & Case 1 & Case 2 & Case 3 & Case 4 & Case 5 \\
\cline { 2 - 6 } & \multicolumn{5}{c}{$w$ \%, normalized } \\
\hline $\mathrm{SiO}_{2}$ & 16.92 & 18.92 & 30.09 & 38.2 & 47.52 \\
$\mathrm{Al}_{2} \mathrm{O}_{3}$ & 9.33 & 8.06 & 7.98 & 6.9 & 5.64 \\
$\mathrm{Fe}_{2} \mathrm{O}_{3}$ & 13.64 & 7.54 & 4.67 & 2.44 & 1.04 \\
$\mathrm{CaO}$ & 28.62 & 24.03 & 18.9 & 15.7 & 4.51 \\
$\mathrm{MgO}$ & 9 & 10.27 & 10.15 & 11.54 & 12.6 \\
$\mathrm{~K} 2 \mathrm{O}$ & 0.19 & 2.13 & 4.23 & 6.74 & 7.87 \\
$\mathrm{Na}_{2} \mathrm{O}$ & 3.95 & 3.84 & 2.72 & 2.21 & 1.97 \\
\hline
\end{tabular}


The ash fusion temperatures (AFTs) were calculated using an ash melting point apparatus according to the GB/T 219-2008 standard. The ash samples were crushed to $100 \mu \mathrm{m}$ and then formed into a pyrometric cone $20 \mathrm{~mm}$ high with $7 \mathrm{~mm}$ equilateral triangular base. The pyrometric cone was placed into an auto-analyzer to measure the ash fusion temperature. The heating rate was set at 15 $20{ }^{\circ} \mathrm{C} / \mathrm{min}$ below $900{ }^{\circ} \mathrm{C}$ and $5{ }^{\circ} \mathrm{C} / \mathrm{min}$ above $900{ }^{\circ} \mathrm{C}$ in a reducing, oxygen free atmosphere. The reducing atmosphere consisted of $\mathrm{CO}$ and $\mathrm{CO}_{2}$ at the mole ratio of 1:1. Four characteristic temperatures of the ash samples were obtained in this study: the deformation temperature (DT), soft temperature (ST), hemisphere temperature (HT) and fluid temperature (FT).

\subsection{X-ray diffraction analysis}

X-ray diffraction (XRD) measurements were used to detect the mineral structures in the ash of different samples. The XRD measurements were recorded on a Rigaku D/max 2550PC diffractometer using $\mathrm{Cu} \mathrm{K}-\alpha$ radiation and operated at $40 \mathrm{kV}$ and $40 \mathrm{~mA}$ with a scanning rate of $4 \%$ min over the range of $2 \theta=20^{\circ} \sim 80^{\circ}$.

\section{Results and discussions}

\subsection{Inter-conversion of sodium and potassium compound classes under co-firing}

The coal, biomass and blended samples were burnt in a muffle furnace at $815{ }^{\circ} \mathrm{C}$ to produce ash according to the Chinese National Standard GB/T 1574-2007. By performing the ICP-AES measurements for the raw fuel and the residual ash, the different classes of sodium released during combustion can be quantified. Owing to the differences in physical structures and chemical compositions of the biomass and the coal, co-firing of the fuel blend changes the combustion characteristics and ash formation. Consequently, the classes and the release dynamics of alkali metals 
will also be influenced. The compound classes of the alkali metals for the biomass, the coal and the blends are shown in Table 3. The values given in the table are the mass of an alkali compound in the initial 1-gram fuel mixture. Only the insoluble alkali metals showed little changes, while the other three classes showed obvious differences for the 5 cases studied. In the coal, the concentration of sodium species was relatively high, while the potassium concentration was extremely low; biomass exhibits the opposite characteristic, high potassium concentration and low sodium concentration. Before burning, the sodium and potassium compositions in the fuel mixture were a linear combination of the sodium and potassium proportion in the two fuels; however, combustion alters the relative concentrations of the various alkali classes, as shown in Figs. 1 and 2. The release of different alkali classes plotted in each figure was calculated from the values in Table 3 as the difference in alkali concentration for each class in the fuel and ash. Here, the amount of each alkali class released in the gas phase (the release amount) and the release ratio were calculated by

$$
\begin{aligned}
& \text { release amount of class } i=M_{i, \text { fuel }}-M_{i, \text { ash }} \\
& \text { release ratio of class } i=\text { release amount of class } i / M_{i, \text { fuel }} \times 100 \%
\end{aligned}
$$

respectively. $M_{i, f u e l}$ is the mass of alkali class $i$ in the fuel mixture, $M_{i, a s h}$ is the mass of alkali class $i$ in the residue, and subscript $i$ denotes one of the four classes of alkali, i.e., water-soluble alkali, $\mathrm{NH}_{4} \mathrm{Ac}$-soluble alkali, $\mathrm{HCl}$-soluble alkali and insoluble alkali. So the release amount gives the information on how much alkali can be released, and the release ratio is a measure of how easily alkali can be released.

Table 3. Amount of different classes of sodium and potassium

\begin{tabular}{cccccccccccc}
\hline & \multicolumn{2}{c}{ Case 1 } & \multicolumn{2}{c}{ Case 2 } & \multicolumn{2}{c}{ Case 3 } & & Case 4 & & \multicolumn{2}{c}{ Case 5 } \\
\cline { 3 - 12 } & & Fuel & Ash & Fuel & Ash & Fuel & Ash & Fuel & Ash & Fuel & Ash \\
\hline \multirow{2}{*}{$\mathrm{Na}$} & Water-soluble & 4.946 & 1.894 & 3.106 & 0.51 & 2.371 & 0.25 & 1.112 & 0.122 & 0.476 & 0.044
\end{tabular}




\begin{tabular}{|c|c|c|c|c|c|c|c|c|c|c|c|}
\hline \multirow[t]{3}{*}{$\mathrm{mg} / \mathrm{g}$ fuel } & $\mathrm{NH}_{4} \mathrm{Ac}$-soluble & 0.55 & 0.095 & 0.521 & 0.087 & 0.342 & 0.044 & 0.285 & 0.033 & 0.232 & 0.025 \\
\hline & HCl-soluble & 0.334 & 0.31 & 0.329 & 0.275 & 0.365 & 0.251 & 0.432 & 0.282 & 0.434 & 0.271 \\
\hline & Insoluble & 1.579 & 1.593 & 1.474 & 1.451 & 1.326 & 1.347 & 1.248 & 1.235 & 0.996 & 0.974 \\
\hline \multirow{4}{*}{$\mathrm{mg} / \mathrm{g}$ fuel } & Water-soluble & 0.046 & 0.024 & 2.41 & 0.671 & 5.883 & 0.771 & 9.517 & 0.835 & 11.72 & 0.58 \\
\hline & $\mathrm{NH}_{4} \mathrm{Ac}$-soluble & 0.038 & 0.004 & 0.153 & 0.022 & 0.245 & 0.046 & 0.451 & 0.135 & 0.574 & 0.23 \\
\hline & HCl-soluble & 0.016 & 0.01 & 0.051 & 0.041 & 0.107 & 0.064 & 0.172 & 0.102 & 0.198 & 0.06 \\
\hline & Insoluble & 0.074 & 0.076 & 0.186 & 0.181 & 0.329 & 0.332 & 0.461 & 0.463 & 0.583 & 0.609 \\
\hline
\end{tabular}

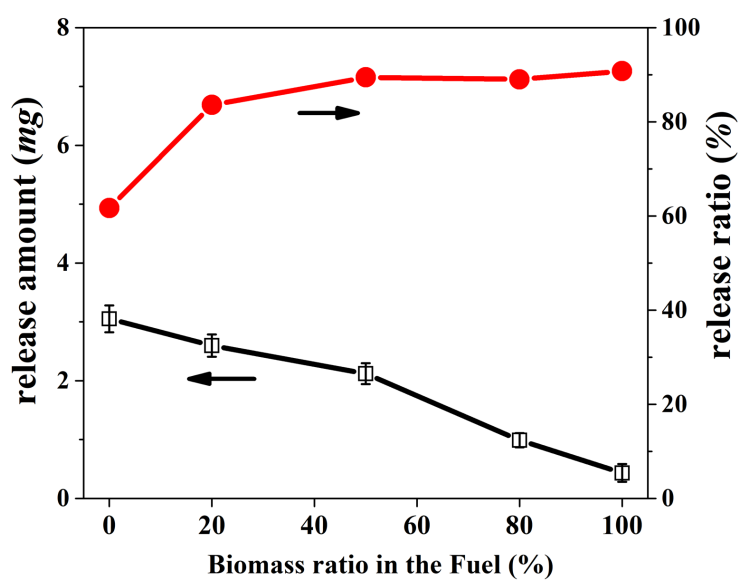

(a) Water-soluble sodium

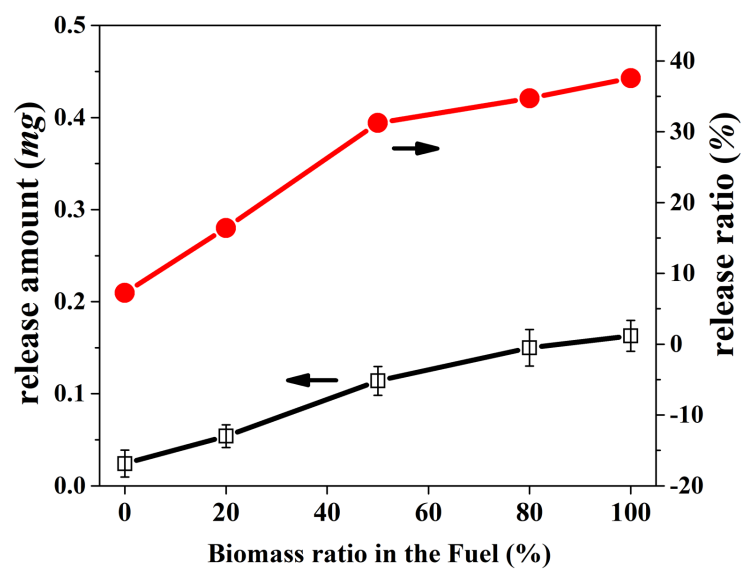

(c) HCl-soluble sodium

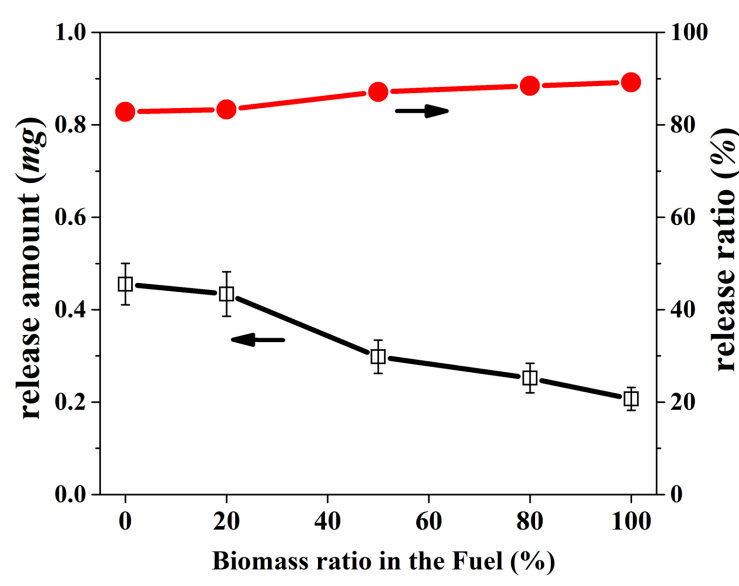

(b) $\mathrm{NH}_{4} \mathrm{Ac}$-soluble sodium

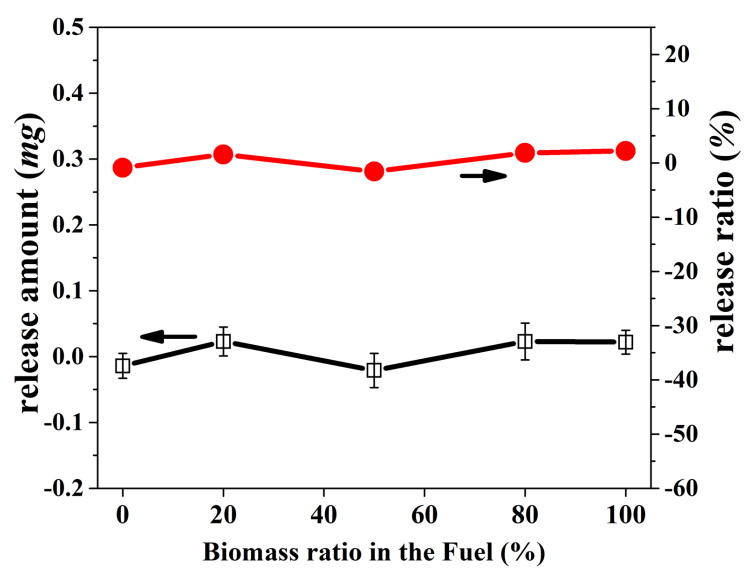

(d) Insoluble sodium

Figure 1. Effect of co-firing on release and transformation of different sodium classes. (calculated based on sodium in blended fuel and corresponding ash) 


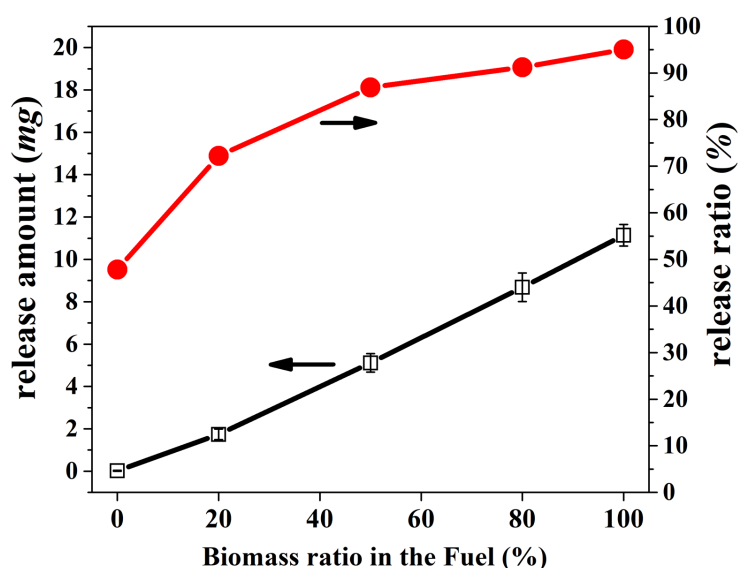

(a) Water-soluble potassium

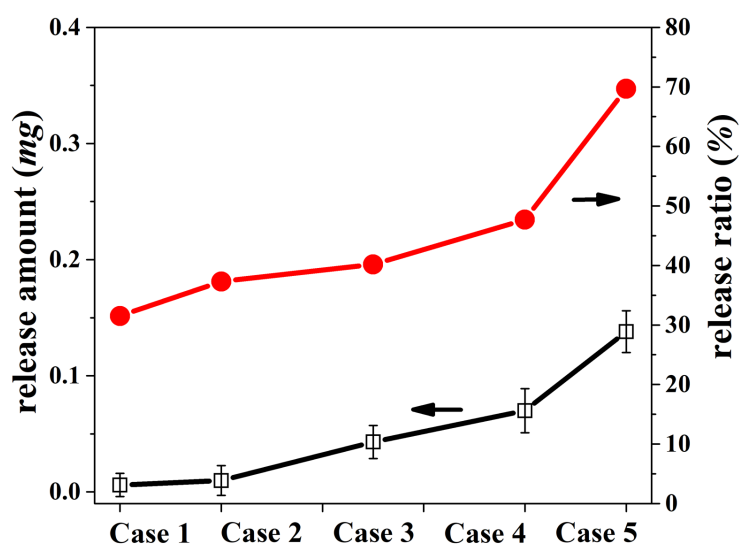

(c) $\mathrm{HCl}$-soluble potassium

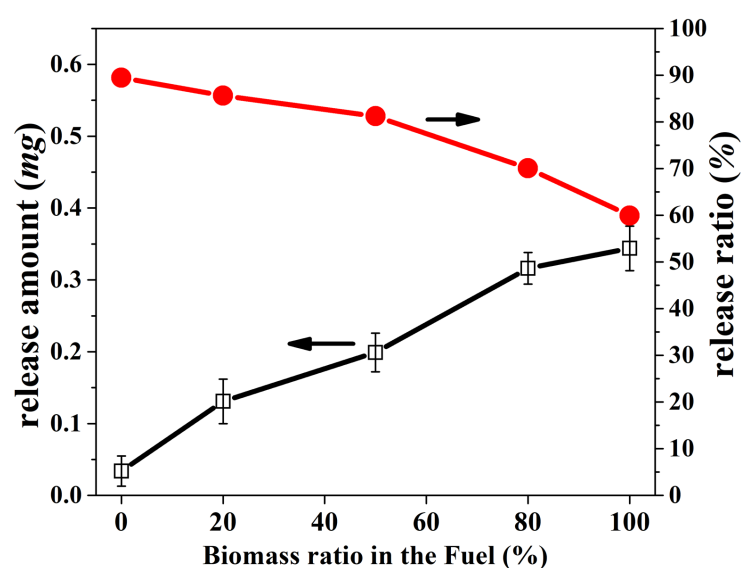

(b) $\mathrm{NH}_{4} \mathrm{Ac}$-soluble potassium

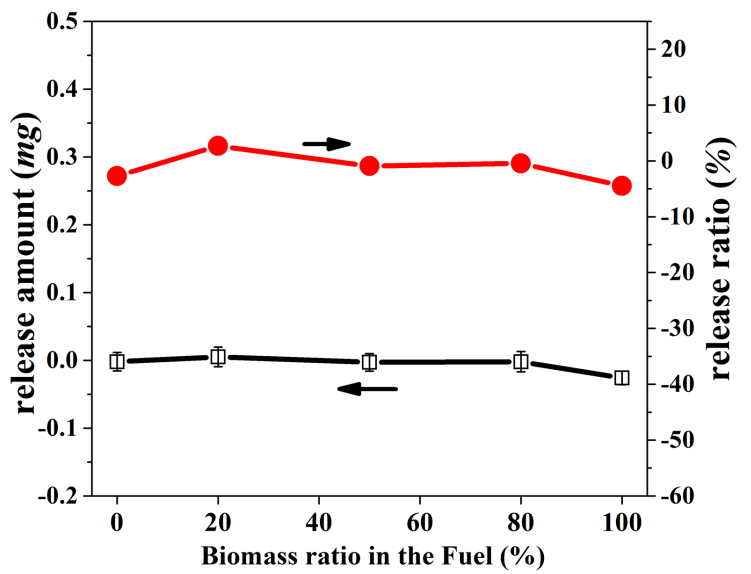

(d) Insoluble potassium

Figure 2. Effect of co-firing on release and transformation of different potassium classes. (calculated

based on potassium in blended fuel and corresponding ash)

The amount of water-soluble sodium, which is the most abundant sodium class and is easily released during combustion [38], decreased noticeably as the biomass proportion increased. Considering the release ratio of water-soluble sodium, it is apparent that the coal/biomass blend released a larger percentage of $\mathrm{Na}$ in the gas phase than the unblended coal sample (Case 1). This trend can also be observed for $\mathrm{NH}_{4} \mathrm{AC}$-soluble sodium, which is the second most prevalent sodium class. The explanation for the increase of the release ratio for these two sodium classes as the biomass proportion increases is that the increased volatile matter (see Table 1) enhances the initial burning of the blended fuel (detailed in section 3.2). The release of these two classes of sodium are closely related to the initial outgassing 
process and therefore the burning temperature [29]. In addition, alkali release has been found in strong correlation with the interaction between volatile and char $[24,25]$ and the increase of volatile matter can enhance the volatile-char interaction. Therefore, the addition of the biomass in the coal not only decreases the sodium concentration of the fuel mixture, but also enhances sodium release through enhanced combustion. For the coal, the release amount and release ratio of $\mathrm{HCl}$-soluble sodium were lowest among the examined fuel mixtures. Adding biomass to the coal can increase both the release amount and release ratio of $\mathrm{HCl}$-soluble sodium. According to Zhang et al. [39], the water-soluble and $\mathrm{NH}_{4} \mathrm{Ac}$-soluble sodium can react with the aluminosilicates and transform to $\mathrm{HCl}$-soluble sodium. In addition, water-soluble sodium can react with organic structure and generate $\mathrm{HCl}$-soluble sodium like (-CONa and -COONa) [40]. Since the aluminosilicate concentration in the residues of the coal is higher than in the residues of the biomass, increasing the biomass proportion in the mixed fuel will weaken the transformation, which makes the release of $\mathrm{HCl}$-soluble sodium more significant.

Potassium and sodium belong to the periodic group I, alkali metals, and are expected to demonstrate similar chemical characteristics. As the biomass contains much more potassium than the coal, increasing the biomass proportion in the fuel blend increases all classes of potassium. As with sodium, water-soluble potassium was the most prevalent potassium class. Consequently, as the proportion of the biomass in the fuel blend increased, both the release ratio and release amount of water-soluble potassium also increased. This release was strengthened by volatile components of the biomass, which intensified the outgassing process due to enhanced combustion during the initial stage. $\mathrm{NH}_{4} \mathrm{Ac}$-soluble potassium showed an increased release amount during combustion as the biomass proportion increases; however, the release ratio of $\mathrm{NH}_{4} \mathrm{Ac}$-soluble potassium decreased as the biomass proportion in the fuel blend increases. Water-soluble potassium reacts with $\mathrm{SiO}_{2}$ in the ash and forms 
$\mathrm{NH}_{4} \mathrm{Ac}$-soluble potassium [39]. Increasing the biomass proportion significantly increases the amount of $\mathrm{SiO}_{2}$ in the residue which promotes this reaction with the net effect that the release ratio of $\mathrm{NH}_{4} \mathrm{Ac}$-soluble potassium decreases. For $\mathrm{HCl}$-soluble potassium, the release amount and release ratio in the gas phase monotonically increase with the biomass proportion in the fuel blend. This is due to the greater amount of all potassium classes in the biomass and aluminosilicate, which promotes the formation of $\mathrm{HCl}$-soluble potassium, decreasing in the ash.

These results provide useful information in the application of Zhundong and corn stalk combustion: water-soluble alkali is the main form alkali released during combustion of these two fuels. In light of this, the optimal means to reduce alkali release would either be removal by prewashing of the coal/biomass or by adding additives to transfer water-soluble alkali into stabile forms [41].

\subsection{In-situ measurement of sodium and potassium release during combustion}

To explore potassium and sodium release in the gas phase during co-firing, LIBS measurements were performed $10 \mathrm{~mm}$ above the burning pellet. The results are shown in Figs. 3 and 4. Comparing the general shape of the release profiles of the two alkalis, the sodium profiles are characterized by a bimodal distribution, while potassium release distributes around a single peak. The coal sample showed the longest duration of sodium release and can be divided into the following three phases of combustion [29, 31]: (a) a volatile release stage (the first peak: $0-64$ s), (b) a char burning stage (the second peak: $64-524 \mathrm{~s})$ and (c) an ash reaction stage (524 - $3013 \mathrm{~s})$. The release mechanism for these three stages can be explained as: (1) during the volatile release stage, the alkali release is due to the physical evaporation and the decomposition of organic compounds [25, 42]; (2) in the char burning stage, the char burnout and the volatile-char interaction contribute to the alkali release [24]; (3) in the ash reaction stage, the alkali release is caused by the reaction between the silicate and $\mathrm{H}_{2} \mathrm{O}$ in the gas phase $[29,43]$. 
The sodium release from biomass was much lower than that from coal, with only the initial peak clearly evident. For potassium, no bimodal curve was evident for any of the fuel mixtures. The potassium signal during coal combustion was too low to be detected. The time when a peak was found and the corresponding peak values are listed in Table 4. $t_{V, N a}$ and $t_{V, K}$ are the time during the volatile stage at which the peak of the sodium and potassium concentrations occur, respectively; $R_{V, N a}$ and $R_{V, K}$ are the corresponding peak magnitudes. $t_{C, N a}$ is the time at which the peak of the sodium concentration occurs during the char burning stage and $R_{C, N a}$ is the corresponding peak magnitude; $t_{e n d, N a}$ and $t_{e n d, K}$ are the time at which sodium and potassium release ends, respectively.

The sodium release profiles and the derived statistics demonstrate the influence of various changes in combustion as the fuel composition is varied.

(i) At low proportions of biomass addition, e.g. Case 1 and Case 2, the sodium signal decreased appreciably from dilution, but the bimodal shape of the release curve is preserved.

(ii) A moderate proportion of biomass in the fuel blend gives enhanced ignition and initial combustion (comparing Case 2 and Case 3), thereby shortening the duration of combustion [44]. The second peak is shifted left towards an earlier time and merges with the first peak.

(iii) At very high biomass proportions the sodium concentration is significantly decreased. The magnitude of the first peak as well as the magnitudes of the whole profile decrease (Case 3 and Case 4).

Across these three regions, the sodium concentration continually decreased as the biomass proportion increased and the combustion period continuously shortens, causing the peak during the char burning stage to shift to increasingly earlier times.

The release profile of potassium had only one peak, which appeared during the initial burning stage. 
Biomass, which has the highest potassium concentration, showed potassium release in the char combustion phase. This was not seen for the blended fuels or the coal. As the coal proportion in the fuel blend increased, the peak magnitude of the potassium concentration significant decreased. Also, the full duration at half maximum (FDHM) of the peak potassium concentration increased because the burning rate decreases. As the coal proportion in the fuel blend increases, the slower burning shifts the location of the potassium concentration to move progressively to later times.

Based on these measured alkali release characteristic, in real industrial application, co-firing a coal-rich blended fuel the primary concern regarding alkali based fouling and corrosion is release of sodium, especially during the char burnout period. When co-firing a biomass-rich blended fuel, the greatest concern is potassium and, the highest risk for damage occurs during the initial combustion period.

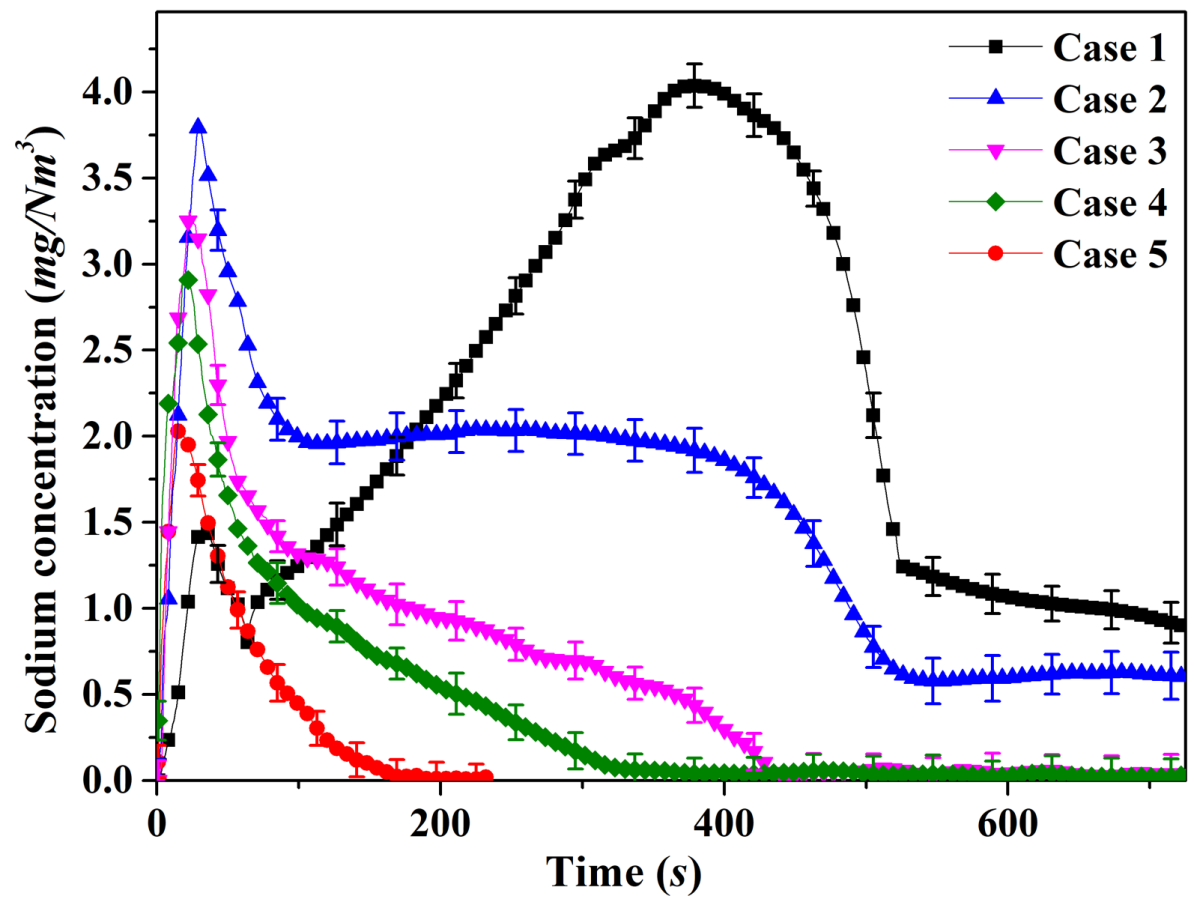

Figure 3. Temporal release of sodium 


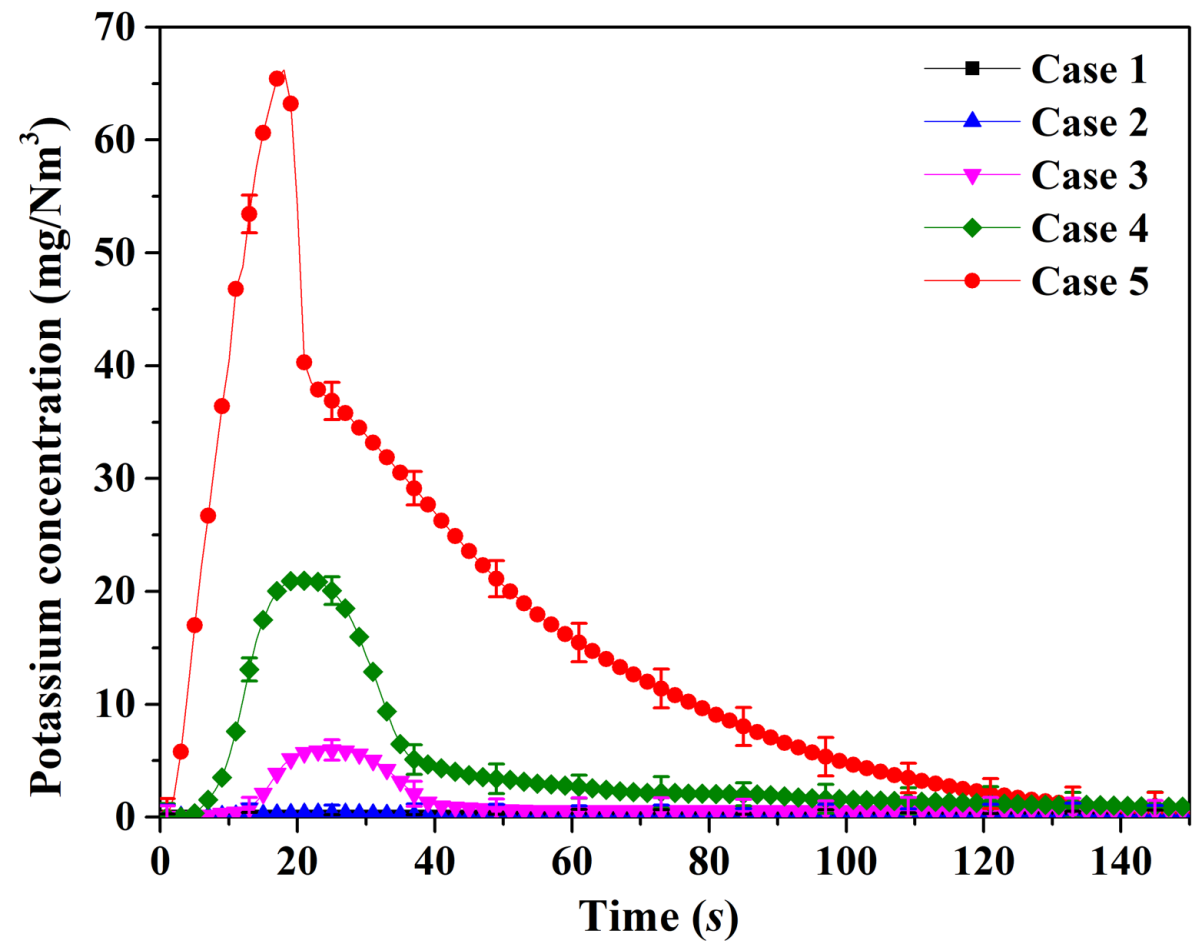

Figure 4. Temporal release of potassium

Table 4 Statistics of sodium and potassium release.

\begin{tabular}{ccccccc}
\hline & & Case 1 & Case 2 & Case 3 & Case 4 & Case 5 \\
\hline & $t_{V, N a}(s)$ & 37 & 29 & 25 & 20 & 16 \\
& $R v_{, N a}\left(m g / N m^{3}\right)$ & 1.4 & 3.7 & 3.3 & 2.9 & 2.0 \\
$\mathrm{Na}$ & $t_{C, N a}(s)$ & 380 & 286 & - & - & - \\
& $R_{C}\left(\mathrm{mg}_{/ \mathrm{Nm}}{ }^{3}\right)$ & 4.0 & 2.1 & - & - & - \\
& $t_{\text {end }}(s)$ & 3013 & 1566 & 1345 & 1141 & 206 \\
\hline \multirow{3}{*}{$\mathrm{K}$} & $t_{V}(s)$ & - & 22.6 & 25.8 & 21.6 & 17.6 \\
& $\left.R_{V}(\mathrm{mg} / \mathrm{Nm})^{3}\right)$ & - & 0.7 & 6.0 & 21.1 & 65.8 \\
& $t_{\text {end }}(s)$ & - & 38 & 53 & 108 & 134 \\
\hline
\end{tabular}

\subsection{X-ray diffraction and phase diagram analysis of minerals formation in ash}

The detailed chemical compositions of the co-firing residues were obtained by XRD and are shown 
in Fig. 5. In agreement with the ash compositions discussed in section 2.4, the largest mineral compositions in the coal are Ca compounds, with Fe compounds being second in abundance. For the biomass, concentrations of mineral species rank as $\mathrm{Si}>\mathrm{Mg}>\mathrm{K}$.

From XRD results, the main minerals in the coal (Case 1) were $\mathrm{CaSO}_{4}, \mathrm{CaO}$, and $\mathrm{Fe}_{2} \mathrm{O}_{3}$. Meanwhile, some albites were detected due to the high Na concentration in the coal. The major minerals in the ash of the biomass (Case 5) were quartz, $\mathrm{K}_{2} \mathrm{SO}_{4}$, and calcium akermanite. The diffraction patterns of $\mathrm{KCl}$ and potassium feldspar can be ascribed to the high potassium concentration in the ash of the biomass. Above all, the XRD results were in good agreement with the elemental composition analysis results in 2.4. The progression of the mineral distribution is observed in the XRD spectra shown in Fig. 5. As the biomass proportion in the fuel blend increases, albite disappears and the peaks of $\mathrm{CaSO}_{4}$ and $\mathrm{CaO}$ decline. Simultaneously, diffraction patterns of potassium feldspar and $\mathrm{K}_{2} \mathrm{SO}_{4}$ appear and increase with the increasing proportion of biomass. The decrease of calcium compounds and the increase of magnesium compounds leads to the appearance of akemanite, which declined after initially increasing with increased biomass proportion.

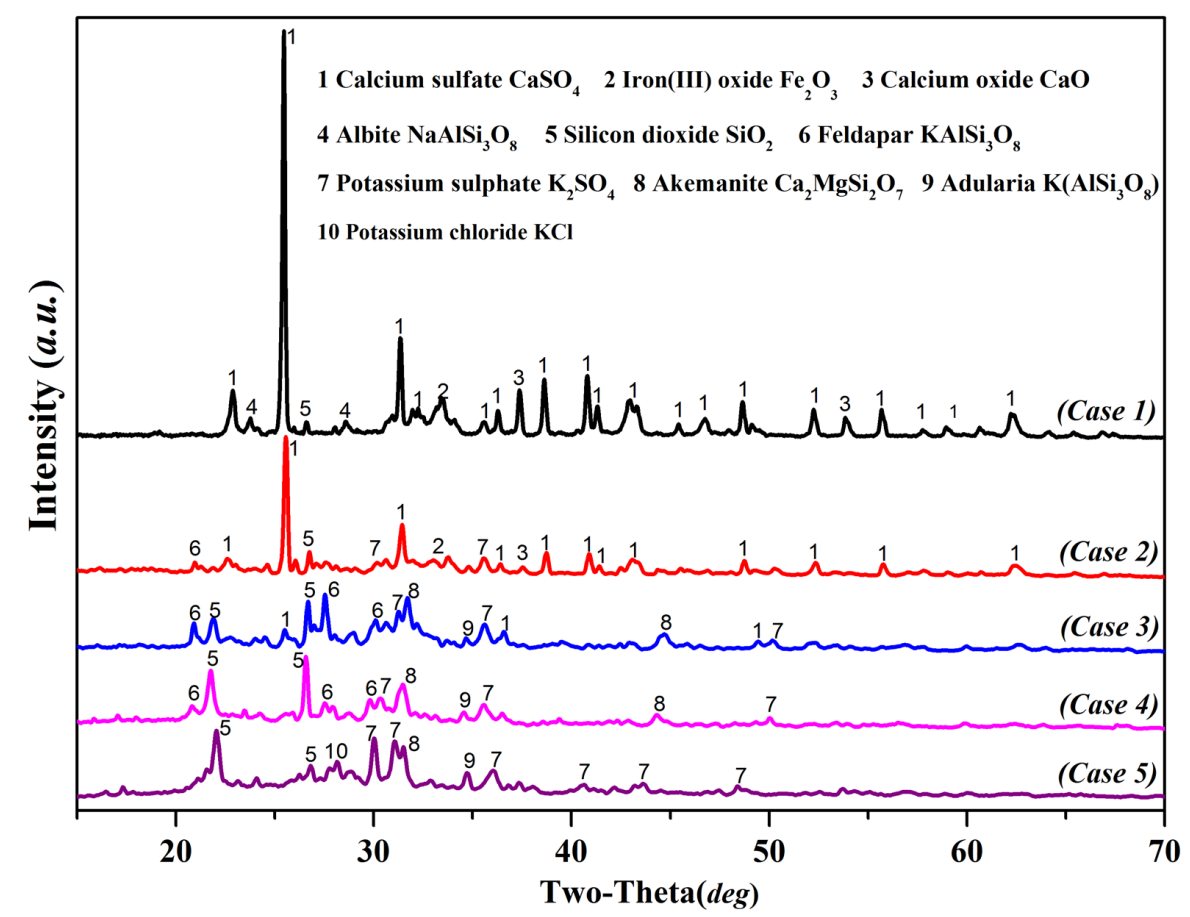


Figure 5. XRD analysis of ash samples.

Table 5 Intensity statistics of minerals in the fuel blends.

\begin{tabular}{|c|c|c|c|c|c|c|}
\hline & & Case 1 & Case 2 & Case 3 & Case 4 & Case 5 \\
\hline \multirow{10}{*}{ 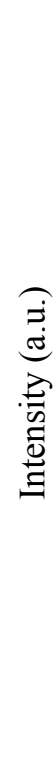 } & Calcium sulfate & 35848 & 12569 & 2122 & 1630 & 0 \\
\hline & Iron(III) oxide & 3633 & 2026 & 0 & 0 & 0 \\
\hline & Calcium oxide & 4359 & 2073 & 0 & 0 & 0 \\
\hline & Albite & 1965 & 0 & 0 & 0 & 0 \\
\hline & Quartz & 1595 & 2047 & 4749 & 6698 & 6780 \\
\hline & Feldapar & 0 & 1393 & 2858 & 2807 & 0 \\
\hline & Potassium sulphate & 0 & 1661 & 3132 & 2988 & 5546 \\
\hline & Akemanite & 0 & 0 & 5085 & 4280 & 3841 \\
\hline & Adularia & 0 & 0 & 1514 & 1745 & 2539 \\
\hline & Potassium chloride & 0 & 0 & 0 & 0 & 3436 \\
\hline
\end{tabular}

The AFTs of the various samples, including the deformation, soft, hemisphere and fluid temperatures are displayed in Fig. 6(a). Zhundong coal is categorized as a type of high ash fusion temperature coal, while cornstalk is a typical type of low ash fusion temperature biomass. For the blended fuels, the ash fusion temperatures initially increased and then decreased as the proportion of biomass increased. However, the lowest AFTs were observed in Case 4. When the proportion of biomass further increased, the AFTS rose up.

The liquidus temperatures can be obtained from a $\mathrm{SiO}_{2}-\mathrm{CaO}-\mathrm{MgO}-\mathrm{Al}_{2} \mathrm{O}_{3}$ ternary phase diagram, which was calculated by Factsage [45] using the phase diagram module. Figure 7 shows the ternary phase diagram of $\mathrm{SiO}_{2}-\mathrm{CaO}-\mathrm{MgO}-\mathrm{Al}_{2} \mathrm{O}_{3}$ with the mass fraction of $\mathrm{Al}_{2} \mathrm{O}_{3}$ fixed at $10 \%$. The locations of the different residues (Case 1 - Case 5), according to their chemical composition analysis, were marked 
on the plot by an ' $x$ ' symbol. The mineral matter in the primary crystal region of Case 1 and Case 2 was the monoxide. With the increase of $\mathrm{SiO}_{2}$ concentration and the drop of $\mathrm{MgO}$ and $\mathrm{CaO}$ concentrations, the primary crystal region changed from akermanite to diopdside, and then finally to quartz. This is not fully consistent with the experimental results (Case 1 and Case 2) shown in Fig. 5, which can be explained by that some elements (such as $\mathrm{K}$ and $\mathrm{Fe}$ ) were not considered in the ternary phase diagram analysis.

The liquidus temperatures indicated in the ternary phase diagram are summarized in Fig. 6(b). It can be found that the trend of the liquidus temperatures (Fig. 6(b)) varying with the biomass proportion was consistent with the results of the AFTs (Fig. 6(a)). Because the mineral matter in the primary crystal region for Case 1 and Case 2 was largely inconsistent with the XRD analysis, the liquidus temperatures of the two cases were not in good agreement with the AFTs results. But the prediction of the eutectic melting phenomenon leads to a rapid decline of the liquidus temperatures in Case 3 and Case 4, which agrees well with the AFTs. In these two cases, the rapid decline of the liquidus temperatures suggests that the interactions between coal and biomass have generates crystalline compounds causing the eutectic melting phenomenon. Both the generation of potassium feldspar observed by XRD and the generation of diopside predicted by the ternary diagram can well explain this phenomenon. The rate of change of the liquidus temperature between Case 4 and Case 5 was quicker than that of the AFTs, which may be due to the lack of potassium in the Factsage simulations.

Occurrence of the eutectic melting phenomenon can cause severe issues in real co-firing systems, which therefore should be avoided. Both AFTs and phase diagrams are useful for predicting this phenomenon. 


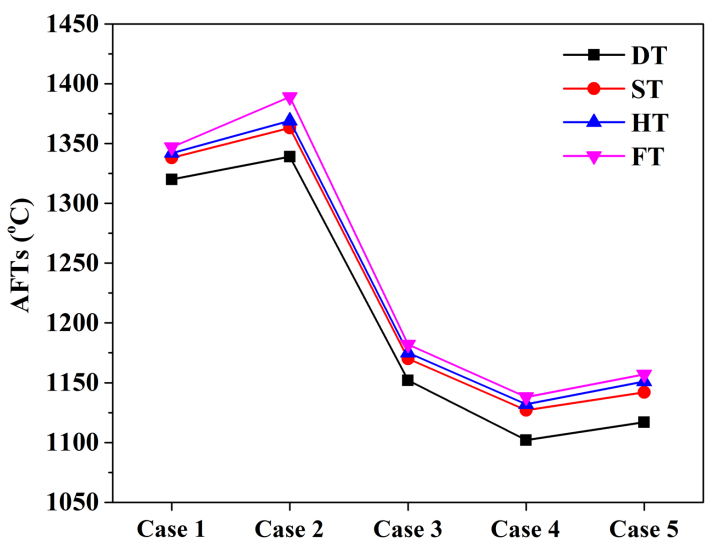

(a) AFTs

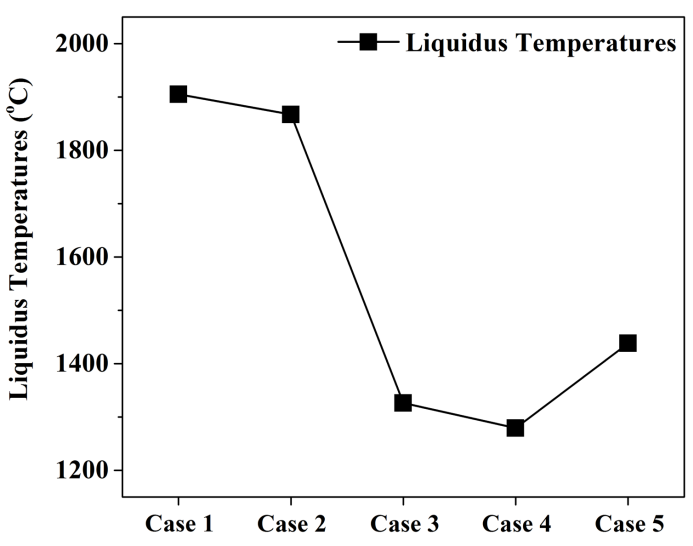

(b) Liquidus temperatures

Figure 6. Comparison of AFTs and liquidus temperatures.

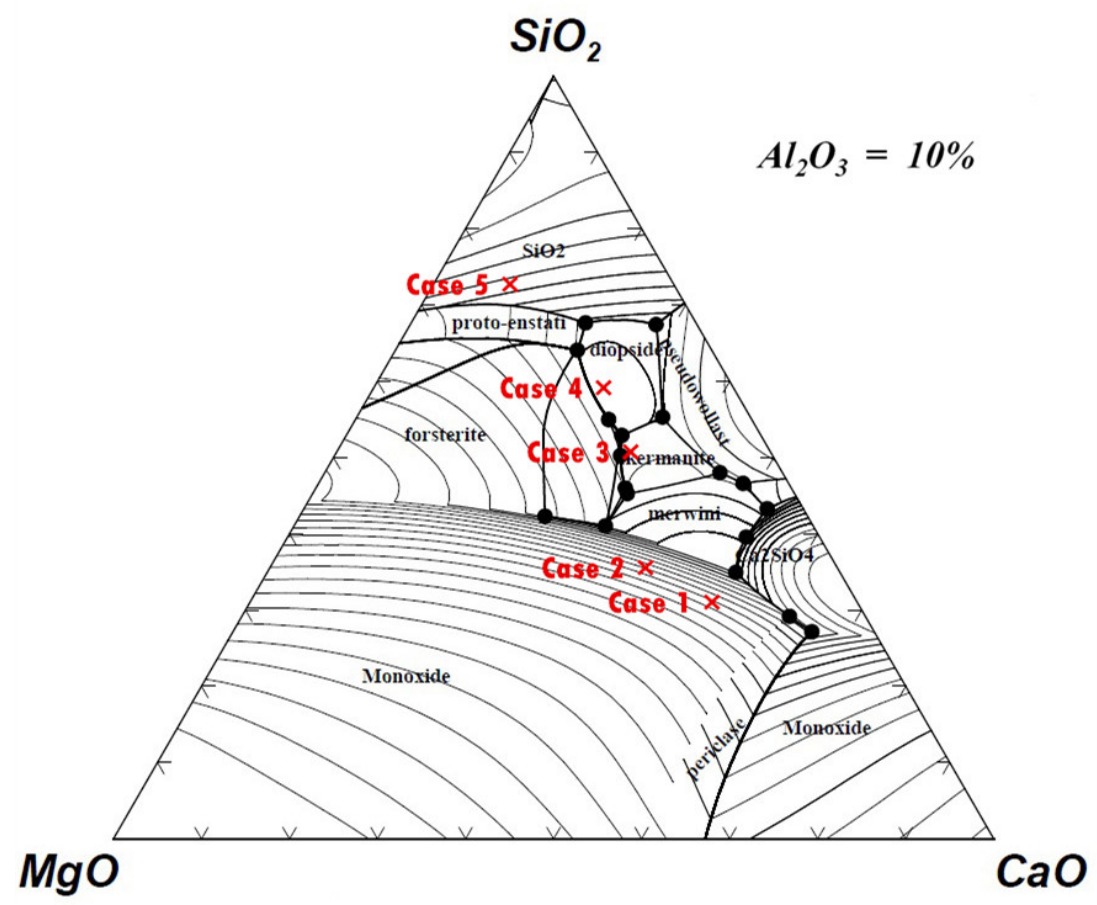

Figure 7. $\mathrm{SiO}_{2}-\mathrm{MgO}-\mathrm{CaO}-\mathrm{Al}_{2} \mathrm{O}_{3}$ ternary phase diagram.

\section{Conclusions}

The composition of alkali in the solid fuel blends is a linear combination of the alkali contained in Zhundong coal and corn stalk. Of the four classes of alkali compounds, i.e., water-soluble, $\mathrm{NH}_{4} \mathrm{Ac}$-soluble, $\mathrm{HCl}$-soluble and insoluble, the insoluble class shows a marginal change of the release 
characteristics with different biomass proportion, while the other three classes exhibit varying trends due to the interactions between the alkali compound and various other components in the fuel mixture. As the corn stalk proportion increases, the release ratio of water-soluble, $\mathrm{NH}_{4} \mathrm{Ac}$-soluble and HCl-soluble sodium increases, whereas the corresponding release amount decreases. For potassium, the release ratio of water-soluble and $\mathrm{HCl}$-soluble potassium can be enhanced at high corn stalk proportion conditions, but that of $\mathrm{NH}_{4} \mathrm{Ac}$-soluble potassium decreases.

The measurement of alkali in the gas phase by LIBS show that alkali release occurs earlier when corn stalk is added to Zhundong coal, since the ignition and outgassing process get enhanced.. Due to the low concentration of sodium in the biomass, its addition to the coal dilutes the total sodium and therefore results in a lower sodium release during the char burning stage. Additionally, the enhanced burning rate and the earlier start of the char burning stage lead to an overlap of sodium signals from the devolatilization and char stages. Enhanced combustion causes the devolatilization to be faster, with a consequent increase of the sodium signal. At the highest biomass concentration, only marginal sodium release is associated with the char burning stage and the sodium released during the devolatilization stage is also notably decrease. The corn stalk has a much higher potassium concentration than Zhundong coal. Therefore as the corn stalk proportion of the fuel mixture increases, the potassium release signal also strengthens. However, the peak of singal remains a single centered distribution during the volatile burning stage.

The analysis of element compositions, melting behavior, and XRD of the co-firing residues have been performed. The components containing calcium and sodium decrease sharply along with the increasing proportion of the corn stalk, while the components containing potassium and silicon increase. Furthermore, the interactions between coal and biomass generate crystalline materials causing a eutectic 
melting phenomenon similar to the feldspar in the XRD results and the diopside in the ternary diagram,

which leads to a sharp decline of the AFTs and liquidus temperatures.

\section{Acknowledgments}

This work was supported by the National Natural Science Foundation of China (51706200,

51406178) and the Program of Introducing Talents of Discipline to University (B08026).

\section{Reference}

[1] Moreira D, Pires JCM. Atmospheric CO2 capture by algae: Negative carbon dioxide emission path. Bioresour Technol. 2016;215:371-9.

[2] Loeffler D, Anderson N. Emissions tradeoffs associated with cofiring forest biomass with coal: A case study in Colorado, USA. Appl Energy. 2014;113:67-77.

[3] Lawrence B, Annamalai K, Sweeten JM, Heflin K. Cofiring coal and dairy biomass in a $29 \mathrm{kWt}$ furnace. Appl Energy. 2009;86:2359-72.

[4] Li J, Brzdekiewicz A, Yang W, Blasiak W. Co-firing based on biomass torrefaction in a pulverized coal boiler with aim of 100\% fuel switching. Appl Energy. 2012;99:344-54.

[5] Kabir MR, Kumar A. Comparison of the energy and environmental performances of nine biomass/coal co-firing pathways. Bioresour Technol. 2012;124:394-405.

[6] Spliethoff H, Hein K. Effect of co-combustion of biomass on emissions in pulverized fuel furnaces. Fuel Process Technol. 1998;54:189-205.

[7] Sahu S, Chakraborty N, Sarkar P. Coal-biomass co-combustion: An overview. Renew Sust Energ Rev. 2014;39:575-86.

[8] Sami M, Annamalai K, Wooldridge M. Co-firing of coal and biomass fuel blends. Prog Energy Combust Sci. 2001;27:171-214.

[9] Easterly JL, Burnham M. Overview of biomass and waste fuel resources for power production. Biomass Bioenerg. 1996;10:79-92.

[10] Obernberger I, Biedermann F, Widmann W, Riedl R. Concentrations of inorganic elements in biomass fuels and recovery in the different ash fractions. Biomass Bioenerg. 1997;12:211-24.

[11] Borello D, Venturini P, Rispoli F, Rafael SG. Prediction of multiphase combustion and ash deposition within a biomass furnace. Appl Energy. 2013;101:413-22.

[12] Chen X, Kong L, Bai J, Dai X, Li H, Bai Z, et al. The key for sodium-rich coal utilization in entrained flow gasifier: The role of sodium on slag viscosity-temperature behavior at high temperatures. Appl Energy. 2017;206:1241-9.

[13] Zhou H, Zhou B, Zhang H, Li L. Behavior of fouling deposits formed on a probe with different surface temperatures. Energy Fuels. 2014;28:7701-11.

[14] Gogebakan Z, Gogebakan Y, Selçuk N, Selçuk E. Investigation of ash deposition in a pilot-scale fluidized bed combustor co-firing biomass with lignite. Bioresour Technol. 2009;100:1033-6.

[15] Theis M, Skrifvars B-J, Zevenhoven M, Hupa M, Tran H. Fouling tendency of ash resulting from burning mixtures of biofuels. Part 2: Deposit chemistry. Fuel. 2006;85:1992-2001.

[16] Robinson AL, Junker H, Baxter LL. Pilot-scale investigation of the influence of coal-biomass cofiring 
on ash deposition. Energy Fuels. 2002;16:343-55.

[17] Wang L, Skreiberg Ø, Becidan M, Li H. Investigation of rye straw ash sintering characteristics and the effect of additives. Appl Energy. 2016;162:1195-204.

[18] Häyrinen V, Hernberg R, Aho M. Demonstration of plasma excited atomic resonance line spectroscopy for on-line measurement of alkali metals in a 20kW bubbling fluidized bed. Fuel. 2004;83:791-7.

[19] Abreu P, Casaca C, Costa M. Ash deposition during the co-firing of bituminous coal with pine sawdust and olive stones in a laboratory furnace. Fuel. 2010;89:4040-8.

[20] Theis M, Skrifvars B-J, Zevenhoven M, Hupa M, Tran H. Fouling tendency of ash resulting from burning mixtures of biofuels. Part 3. Influence of probe surface temperature. Fuel. 2006;85:2002-11.

[21] Westberg HM, Byström M, Leckner B. Distribution of potassium, chlorine, and sulfur between solid and vapor phases during combustion of wood chips and coal. Energy Fuels. 2003;17:18-28.

[22] Kwong PC, Chao CY, Wang J, Cheung C, Kendall G. Co-combustion performance of coal with rice husks and bamboo. Atmos Environ. 2007;41:7462-72.

[23] Holtmeyer ML, Kumfer BM, Axelbaum RL. Effects of biomass particle size during cofiring under air-fired and oxyfuel conditions. Appl Energy. 2012;93:606-13.

[24] Wu H, Quyn DM, Li C-Z. Volatilisation and catalytic effects of alkali and alkaline earth metallic species during the pyrolysis and gasification of Victorian brown coal. Part III. The importance of the interactions between volatiles and char at high temperature. Fuel. 2002;81:1033-9.

[25] Long J, Song H, Jun X, Sheng S, Lun-shi S, Kai X, et al. Release characteristics of alkali and alkaline earth metallic species during biomass pyrolysis and steam gasification process. Bioresour Technol. 2012;116:278-84.

[26] Sorvajärvi T, DeMartini N, Rossi J, Toivonen J. In situ measurement technique for simultaneous detection of $\mathrm{K}, \mathrm{KCl}$, and $\mathrm{KOH}$ vapors released during combustion of solid biomass fuel in a single particle reactor. Appl Spectrosc. 2014;68:179-84.

[27] Erbel C, Mayerhofer M, Monkhouse P, Gaderer M, Spliethoff H. Continuous in situ measurements of alkali species in the gasification of biomass. Proc Combust Inst. 2013;34:2331-8.

[28] Weng W, Gao Q, Wang Z, Whiddon R, He Y, Li Z, et al. Quantitative measurement of atomic potassium in plumes over burning solid fuels using infrared-diode laser spectroscopy. Energy Fuels. 2017;31:2831-7.

[29] Van Eyk PJ, Ashman PJ, Nathan GJ. Mechanism and kinetics of sodium release from brown coal char particles during combustion. Combust Flame. 2011;158:2512-23.

[30] Hsu L-J, Alwahabi ZT, Nathan GJ, Li Y, Li Z, Aldén M. Sodium and potassium released from burning particles of brown coal and pine wood in a laminar premixed methane flame using quantitative laser-induced breakdown spectroscopy. Appl Spectrosc. 2011;65:684-91.

[31] He Y, Zhu J, Li B, Wang Z, Li Z, Aldén M, et al. In-situ measurement of sodium and potassium release during oxy-fuel combustion of lignite using laser-induced breakdown spectroscopy: effects of $\mathrm{O} 2$ and $\mathrm{CO} 2$ concentration. Energy Fuels. 2013;27:1123-30.

[32] Zhou J, Zhuang X, Alastuey A, Querol X, Li J. Geochemistry and mineralogy of coal in the recently explored Zhundong large coal field in the Junggar basin, Xinjiang province, China. Int J Coal Geol. 2010;82:51-67.

[33] Junfeng L, Runqing H, Yanqin S, Jingli S, Bhattacharya S, Salam PA. Assessment of sustainable energy potential of non-plantation biomass resources in China. Biomass Bioenerg. 2005;29:167-77.

[34] Ge L, Zhang Y, Wang Z, Zhou J, Cen K. Effects of microwave irradiation treatment on physicochemical characteristics of Chinese low-rank coals. Energy Conv Manag. 2013;71:84-91.

[35] Benson SA, Holm PL. Comparison of inorganics in three low-rank coals. Ind Eng Chem Res. 1985;24:145-9. 
[36] Khazraie Shoulaifar T, DeMartini N, Zevenhoven M, Verhoeff F, Kiel J, Hupa M. Ash-Forming matter in torrefied birch wood: Changes in chemical association. Energy Fuels. 2013;27:5684-90.

[37] Wang Z, Liu Y, He Y, Whiddon R, Wan K, Xia J, et al. Effects of Microwave Irradiation on Combustion and Sodium Release Characteristics of Zhundong Lignite. Energy Fuels. 2016;30:8977-84.

[38] He Y, Qiu K, Whiddon R, Wang Z, Zhu Y, Liu Y, et al. Release characteristic of different classes of sodium during combustion of Zhun-Dong coal investigated by laser-induced breakdown spectroscopy. Sci Bull. 2015;60:1927-34.

[39] Zhang J, Han C-L, Yan Z, Liu K, Xu Y, Sheng C-D, et al. The varying characterization of alkali metals (Na, K) from coal during the initial stage of coal combustion. Energy Fuels. 2001;15:786-93.

[40] Guo D-1, Wu S-b, Liu B, Yin X-1, Yang Q. Catalytic effects of $\mathrm{NaOH}$ and $\mathrm{Na} 2 \mathrm{CO} 3$ additives on alkali lignin pyrolysis and gasification. Appl Energy. 2012;95:22-30.

[41] Si J, Liu X, Xu M, Sheng L, Zhou Z, Wang C, et al. Effect of kaolin additive on PM 2.5 reduction during pulverized coal combustion: importance of sodium and its occurrence in coal. Appl Energy. 2014;114:434-44. [42] Wang Z, Liu Y, Whiddon R, Wan K, He Y, Xia J, et al. Measurement of atomic sodium release during pyrolysis and combustion of sodium-enriched Zhundong coal pellet. Combust Flame. 2017;176:429-38.

[43] Liu Y, He Y, Wang Z, Wan K, Xia J, Liu J, et al. Multi-point LIBS measurement and kinetics modeling of sodium release from a burning Zhundong coal particle. Combust Flame. 2018;189:77-86.

[44] Otero M, Sánchez M, Gómez X. Co-firing of coal and manure biomass: A TG-MS approach. Bioresour Technol. 2011;102:8304-9.

[45] Bale C, Chartrand P, Degterov S, Eriksson G, Hack K, Mahfoud RB, et al. FactSage thermochemical software and databases. Calphad-Comput Coupling Ph Diagrams Thermochem. 2002;26:189-228. 